Conclusion The occurrence of a suspected EVD case in any offshore installation or facility will always require a multi-sectoral response. It is a matter of national importance as for example; the principle of quarantine enforced on a host offshore facility will pose practical and epidemiological curiosity; repatriation of affected expatriate workers will require deployment of foreign diplomatic/military missions, and port control formalities installed once a case is declared in-country often requires inter-governmental collaboration. While research continues to study behaviour and pathogenicity of new viral strains of epidemic potential, industry and governments must maintain realistic and regularly 'drilled' pandemic preparedness plans.

\section{FIRST AID IN THE WORKPLACE IN THE WORLD: A SYSTEMATIC REVIEW}

${ }^{1}$ Céline Dagrenat, ${ }^{2}$ Pascal Cassan, ${ }^{2}$ Diane Issard, ${ }^{3}$ Thomas Loeb, ${ }^{3}$ Michel Bae ${ }^{4,5}$ Alexis Descatha. ${ }^{1} \mathrm{C}$ mie, Puteaux, France; ${ }^{2}$ International Federation of Red Cross and Red Crescent Societies, Global First Aid Reference Centre, Paris, France; ${ }^{3}$ AP-HP, EMS (Samu92), University hospital of West suburb of Paris, Poincare site, Garches, France; ${ }^{4} A P-H P, E M S$ (Samu92) Occupational Health Unit, University hospital of West suburb of Paris, Poincaré site, Garches, France; ${ }^{5}$ Population-based Epidemiologic Cohorts Unit, VIMA, Ageing and Chronic Diseases. Epidemiological and Public Health Approaches, Inserm, Villejuif, France

\subsection{6/oemed-2018-ICOHabstracts.324}

Introduction Implementing an effective First Aid system at the workplace is a major challenge taking into account the increasing frequency of cardiovascular disorders, easy access of defibrillators, and legal consequences of injury occurring in this particular setting. The aim of the study was to perform a systematic review to evaluate the current knowledge of First Aid techniques at the workplace.

Methods Five databases (Pub-Med, Web of Science, Science Direct, Institut National de recherche et de Sécurité (INRS) and European Reference Centre for First Aid Education (ERCFAE) were searched since 2000, using the keywords "First aid ", (" Workplace ", or " Occupational disease »). The full-text articles included had to take place at the workplace and to describe a First Aid intervention. A two-stage process with two independent readers was used to select relevant papers.

Results 18 studies were included in the systematic review on the 168 records screened. Studies were mainly from Europe and North America: 5 referred to the regulation of first aid at the workplace, 8 to the organisation, 3 to the training and 2 both to regulation and organisation. Legislation and organisation of the emergencies at the workplace were very different between countries and disparities even existed within a same country. Employees involved in First Aid interventions should benefit from an adequate theoretical and practical training as well as suitable places with an access to the adapted equipment they need. On the training aspect, interest of refresher courses has shown better results in terms of knowledge and theoretical and practical skills.

Conclusion First aid at the workplace seems to be important even if the countries didn't make specific and homogeneous recommendations on the subject. Develop an effective First Aid system at the workplace means acting on occupational injuries and helping to prevent occupational risks.

\section{EARLY DEFIBRILLATION IN WORKPLACES IN ITALY}

B Papaleo*, G Cangiano*, S Calicchia*, M De Rosa*, L Marcellini*. INAIL - National Institute for Insurance against Accidents at work - Department of Occupational and Environmental Medicine, Epidemiology and Hygiene, Monte Porzio Catone (Rome), Italy

\subsection{6/oemed-2018-ICOHabstracts.325}

In Italy the presence of AEDs and people trained is mandatory in sporting centres, while in industrial sites, places with high traffic of people (stations, stadiums, theatres, shopping centres) or isolated and difficult to reach (trains, planes, boats) is, at the moment, only recommended.

In the workplace, the organisation and management of first aid are established by law (Legislative Decree 81/2008 and Ministerial Decree 388/2003): the occupational physician takes care of the organisation of the company's first aid system, while the management in case of incident goes through lay rescuers, specifically identified and properly trained, and the local emergency medical service (EMS).

The first aid training lasts 12-16 hours, with specific learning objectives defined by law, includes about 5 hours of cardio-pulmonary resuscitation manoeuvres. Therefore adding the use of AED to the training program would not entail an additional cost for the companies, both in economic terms and in time. It would only be necessary to respect the internationally agreed features on didactic content, student/instructor relationship, training on manikin, learning test and more frequently retraining. Instead, the benefits would be significant: increase of the efficiency of first aid courses, improvement of public access network to early defibrillation and rise of bystanders able to intervene in case of emergency.

To promote the diffusion of early defibrillation culture INAIL established a discount of insurance premium for those companies that are not required to have an AED, but who choose to have it to protect the health of their employees and customers.

Unfortunately the diffusion of this culture is made difficult by the involvement of various agencies (emergency systems, regional administration) that control the authorisation procedures for AED training often in a different way in the national territory. We therefore hope for greater homogeneity between the various regions and simplification of the procedures.

\section{EVALUATION OF STRESS AND ANXIETY IN A GRIMED POPULATION PLAYING THE ROLE OF VICTIMS IN A LIVE TERRORIST ATTACK EXERCISE}

Thomas Loeb*, Charles Groizard, Anna Ozguler, Catherine Fleischel, Karine Gauthier, Michel Baer. SAMU92, APHP, Garches, France

\subsection{6/oemed-2018-ICOHabstracts.326}

Introduction Emergency Medical Services (EMS) organise simulation exercises in near real conditions. In this exercises, volunteers usually act as victims. We set up a large-scale simulation exercise. The scenario was a terrorist attack causing 153 victims. Victims were played by nurse students. The aim of our study was to evaluate if playing a role of victim could generate stress and anxiety. 